\title{
Gubernaculum Testis
}

National Cancer Institute

\section{Source}

National Cancer Institute. Gubernaculum Testis. NCI Thesaurus. Code C82952.

A peritoneal fold attached to the testis during embryonic development. It is present during the scrotal descend of the testis and it subsequently undergoes atrophy. 